\title{
Agreement between distance and near minus-lens-to-blur amplitude of accommodation in pre-presbyopic subjects
}

\begin{tabular}{|c|c|}
\hline \multicolumn{2}{|c|}{$\begin{array}{l}\text { Authors: } \\
\text { Mbali Z.G. Ndlovu }{ }^{1} \text { (]) } \\
\text { Kgaogelo T. Mothapo }^{1} \text { (1) } \\
\text { Makgatha H. Kgatla }^{1} \text { (1) } \\
\text { Muano S. Tshihomu }^{1} \text { (]) } \\
\text { Solani D. Mathebula }{ }^{1} \text { (]) }\end{array}$} \\
\hline \multicolumn{2}{|c|}{$\begin{array}{l}\text { Affiliations: } \\
{ }^{1} \text { Department of Optometry, } \\
\text { University of Limpopo, } \\
\text { Sovenga, South Africa }\end{array}$} \\
\hline \multicolumn{2}{|c|}{$\begin{array}{l}\text { Corresponding author: } \\
\text { Solani Mathebula, solani. } \\
\text { mathebula@ul.ac.za }\end{array}$} \\
\hline \multicolumn{2}{|c|}{$\begin{array}{l}\text { Dates: } \\
\text { Received: } 27 \text { Nov } 2018 \\
\text { Accepted: } 23 \text { Apr. } 2019 \\
\text { Published: } 24 \text { June } 2019\end{array}$} \\
\hline \multicolumn{2}{|c|}{$\begin{array}{l}\text { How to cite this article: } \\
\text { Ndlovu MZG, Mothapo KT, } \\
\text { Kgatla MH, Tshihomu MS, } \\
\text { Mathebula SD. Agreement } \\
\text { between distance and } \\
\text { near minus-lens-to-blur } \\
\text { amplitude of accommodation } \\
\text { in pre-presbyopic subjects. Afr } \\
\text { Vision Eye Health. 2019;78(1), } \\
\text { a491. https://doi.org/10.4102/ } \\
\text { aveh.v78i1.491 }\end{array}$} \\
\hline \multicolumn{2}{|c|}{$\begin{array}{l}\text { Copyright: } \\
\text { ( 2019. The Author(s) } \\
\text { Licensee: AOSIS. This v } \\
\text { is licensed under the } \\
\text { Creative Commons } \\
\text { Attribution License. }\end{array}$} \\
\hline \multicolumn{2}{|l|}{ Read online: } \\
\hline 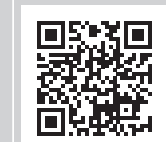 & $\begin{array}{l}\text { Scan this QR } \\
\text { code with your } \\
\text { smart phone or } \\
\text { mobile device } \\
\text { to read online. }\end{array}$ \\
\hline
\end{tabular}

Background: Guidelines for predicting the amplitude of accommodation (AA) sometimes are based on measurements for the subjective push-up-to-blur method. However, the pushup-to-blur method often overestimates the accommodative response. Another method that is commonly used to measure AA is the minus-lens-to-blur technique. This method is routinely conducted at a viewing distance of $40 \mathrm{~cm}$, with the addition of $2.50 \mathrm{D}$ to correspond with the initial accommodative stimulus.

Aim: Although the AA measured using the minus-lens-to-blur method can be performed with the target at $40 \mathrm{~cm}$, this study investigated changing the viewing distance and then comparing the means for participants at $600 \mathrm{~cm}(6 \mathrm{~m}), 40 \mathrm{~cm}(0.4 \mathrm{~m})$ and $33 \mathrm{~cm}(0.33 \mathrm{~m})$. In this manner, the possibility of using the AA measured at $6 \mathrm{~m}$ to estimate AA at $40 \mathrm{~cm}$ or $33 \mathrm{~cm}$ could be explored.

Setting: The study was conducted in the Optometry Department, University of Limpopo.

Methods: The AA was measured using the minus-lens-to-blur method over the distance correction when the target was held at viewing distances of $6 \mathrm{~m}, 40 \mathrm{~cm}$ and $33 \mathrm{~cm}$. The minus lens power used to stimulate accommodation was gradually increased in $0.25 \mathrm{D}$ steps. All measurements were performed using a phoropter.

Results: The mean AA was $8.46 \pm 2.07 \mathrm{D}$ for $6 \mathrm{~m}, 10.62 \pm 2.05 \mathrm{D}$ for $40 \mathrm{~cm}$ and $11.31 \pm 2.07 \mathrm{D}$ for $33 \mathrm{~cm}$. The measured AA at $6 \mathrm{~m}$ was significantly lower than that with the target at $40 \mathrm{~cm}$ and $33 \mathrm{~cm}$ measurement, $p<0.01$. The Bland-Altman plots showed that there was a weaker agreement between the measured AA with the target at $6 \mathrm{~m}$ and near; however, there was a better agreement when the target was at $40 \mathrm{~cm}$ or $33 \mathrm{~cm}$.

Conclusion: The findings of this study suggest that the results for AA measured using the minus-lens-to-blur method at $6 \mathrm{~m}$ are not comparable to the results with the target at $40 \mathrm{~cm}$ or $33 \mathrm{~cm}$. Even though there was a positive correlation between $6 \mathrm{~m}$ and the near distances, the results were not interchangeable or useful to calculate AA at $40 \mathrm{~cm}$ and $33 \mathrm{~cm}$. The difference between the AA measured with the target at $40 \mathrm{~cm}$ and $33 \mathrm{~cm}$ can vary on average by about $0.70 \mathrm{D}$.

Keywords: amplitude of accommodation; blur; dioptre; minus-lens-to-blur method; push-upto-blur method; subjective method.

\section{Introduction}

Accommodation can be defined as an increase in dioptric power of the eye for clearly focusing near objects of regard on the retina. Accommodation results from a change in the shape of the crystalline lens. ${ }^{1,2,3,4,5,6}$ The greatest increase in dioptric or refractive change an eye can undergo is called the amplitude of accommodation (AA). ${ }^{1,2,3,4,5,6}$ The AA decreases with age; young individuals have the greatest amplitude that gradually decreases with age leading to presbyopia (which starts to affect performance with near-visual tasks around 40 years of age). ${ }^{4,5}$ There is little or no accommodative ability left around the age of 55-60 years. ${ }^{5}$

The measurement of the AA is a component of a routine clinical eye examination to detect and manage common refractive conditions, such as latent hyperopia and accommodative insufficiency. A wide range of physiological, optical and other factors has been reported to influence or affect AA measurements. ${ }^{7}$ The significance of these factors is difficult to determine as AA measurements are relatively variable. Hence, the standardisation and improvement of the measurements of AA is essential. 
Amplitude of accommodation is commonly assessed subjectively using the push-up-to-blur or minus-lens-to-blur technique. Both tests require that the subject correctly identifies the moment at which the target fixated on becomes and stays blurred, that is, first sustained blur. Previous studies have tested the accuracy of the push-up-to-blur technique and found that illumination, target size, depth of focus, endpoint criteria, proximal cues and pupil size all affect these measurements. $4,5,6,7,7,9,10,11,12,13,14$ Generally, the push-up-to-blur method overestimates the AA and can suggest that active accommodation is present when it is not. ${ }^{4,5}$ The subjective push-up-to-blur technique overestimates the true AA of the eye due to an increase in proximally induced accommodation and the relative linear magnification of the target. The minuslens-to-blur technique can be performed at a viewing distance of $40 \mathrm{~cm}$ with $2.50 \mathrm{D}$ as the initial accommodative stimulus, added to the distance correction to compensate for $40 \mathrm{~cm}$ and the results recorded as the AA.

The use of computers and handheld smartphones for written communication is becoming ubiquitous in modern society worldwide. $^{15,16,17}$ The relative small screens of smartphones may necessitate closer working distances than $40 \mathrm{~cm}$, and the small text sizes may increase the demands on accommodation and vergence when compared to printed materials. This can result in symptoms such as headache, blurred vision, diplopia, eyestrain, ocular discomfort and dry eye after prolonged use. The closer distances adopted when using smart phones for an extended period may induce a larger lag of accommodation and ocular fatigue. The effect of changing the viewing distance on the clinical measure of AA is relatively unknown.

The purpose of this study was to investigate the effect of the measured AA using the minus-lens-to-blur method with the target at $6 \mathrm{~m}, 40 \mathrm{~cm}$ and $33 \mathrm{~cm}$. The effects of changing the standard viewing distance of AA using the minus-lens-toblur method is not well known; so, it is imperative to know whether changing the target distance will result in a significant difference in the minus-lens-to-blur finding. Measuring AA with the target at a near distance can create problems as more proximal accommodation occurs when the target is placed more closely. The other purpose here was to find out if measured AA with the target at $6 \mathrm{~m}$ could be statistically reliable to calculate AA at the standard measuring distance of $40 \mathrm{~cm}$ and to compare the measured AA with target distances of $33 \mathrm{~cm}$ and $40 \mathrm{~cm}$.

\section{Method}

The study was performed on 50 (31 women and 19 men) university students. The mean age was $23.68 \pm 1.64(18-26)$ years. This project conformed to the principles of the Helsinki Declaration, and the subjects gave their informed consent before starting the study and after an explanation of the nature of the study. Subjects were recruited through posters placed at different noticeboards around the university.

Inclusion criteria were best corrected visual acuity of at least $6 / 6(20 / 20)$ in each eye at both far $(6 \mathrm{~m})$ and near $(40 \mathrm{~cm})$, and there was no history of ocular disease, ocular trauma or refractive surgery. Subjects were excluded if they demonstrated strabismus at far and/or near and systemic illness (diabetes), as well as subjects on any systemic medication that could affect accommodation (such as certain flu medications). Refractive errors were determined using static retinoscopy and refined by subjective refraction to maximum plus while maintaining the best visual acuity. The AA was measured with the target first at far $(6 \mathrm{~m})$ and then at near $(40 \mathrm{~cm}$ and $33 \mathrm{~cm})$ using minus-lens-to-blur method. Although AA was measured monocularly for both eyes of all participants, only results for the right eyes were used here for the analysis. Data from two eyes of one healthy individual are likely to be correlated (except in cases such as keratoconus); so, to avoid possible confounding of correlation and regression analyses, only the measurement of the AA from one eye of each participant was used for analysis.

In normal room illumination, each participant was directed to the 6/9 row of letters on the distance Snellen chart for measuring AA at $6 \mathrm{~m}$ or the row of 20/30 letters on reduced Snellen chart for $40 \mathrm{~cm}$ or a row of 20/25 letters for $33 \mathrm{~cm}$. The minus lens power (sphere) was gradually increased in $0.25 \mathrm{D}$ steps over-and-above the subjective refractive correction until the letters became slightly blurry and could not be cleared by the participant. For the near measurements $(40 \mathrm{~cm}$ and $33 \mathrm{~cm})$, the reduced Snellen chart was placed on a reading stand perpendicular to the line of sight of the subjects. The subjects indicated the first moment when the target became and remained slightly blurred. The last lens of negative lens power that produced the first noticeable blur point when the subject could not focus clearly on the target by making a conscious accommodative effort was recorded as the subject's AA for the distance. For each viewing distance, three measurements were averaged with 10-minute breaks in between. All measurements were performed, while the other eye was fully occluded. The AA was then recorded as the amount of the minus lens power added before the subject reported the first slight sustained blur, plus the dioptric value of the test distance, $2.50 \mathrm{D}$ for $40 \mathrm{~cm}$ and $3.00 \mathrm{D}$ for $33 \mathrm{~cm}$. In the minus-lens-to-blur method, negative or minus spherical lenses are added to the distance refractive compensation until the participant cannot maintain clarity. ${ }^{3,13}$ The AA is given by the maximum negative lens power added and the working distance lens of either $2.50 \mathrm{D}$ for $40 \mathrm{~cm}$ or $3 \mathrm{D}$ for $33 \mathrm{~cm}$. However, Scheiman and Wick ${ }^{18}$ suggested that for the minus lens method, the target should be placed at $33 \mathrm{~cm}$ so as to compensate for the effect of minification, but only $2.50 \mathrm{D}$ instead of $3 \mathrm{D}$ should be added to the result to account for the working distance. Again, the measured AA with the target at $33 \mathrm{~cm}$ was recorded as the amount of the minus lens power added before the subject plus $2.50 \mathrm{D}$ for $33 \mathrm{~cm}$.

\section{Statistical analysis}

The data were analysed using the Statistical Package for Social Sciences (SPSS) version 24 (SPSS Inc. Chicago, IL, United States) and descriptive statistics such as means and 
standard deviation were obtained. The $t$-test and regression analysis were used to assess correlation. The Bland-Altman method was used to assess the agreement between the AA measured for different viewing distances. This method is used by both researchers and/or clinicians to establish the criteria as to whether or not a difference is significant. ${ }^{13}$ Given the sample size here, a small difference could be statistically significant yet not clinically significant. Differences from the bias (mean differences) were plotted to establish the 95\% limits of agreement. The limits of agreement were calculated as mean difference \pm 1.96 (standard deviation [s.d.]). The intraclass correlation coefficient (ICC) was used to determine the reliability of the test at $6 \mathrm{~m}, 40 \mathrm{~cm}$ and $33 \mathrm{~cm}$. The significance level was considered as $p<0.05$ in all tests.

\section{Ethical considerations}

The ethical clearance to conduct this study was obtained from the Turflop Research Ethics Committee, University of Limpopo (Ethical Clearance number: TREC/196/2015: IR).

\section{Results}

Fifty participants $(N=50)$ participated in the study. However, four of them were excluded (as outliers) from further analysis performed on the remaining 46 subjects aged between 20 and 24 years with a mean and standard deviation of $22.20 \pm 1.23$ years. The mean and standard deviation of refractive error spherical equivalent were $+0.25 \pm 0.50 \mathrm{D}$ with a range of -0.25 to $+0.75 \mathrm{D}$.

Table 1 shows the normality test using the KolmogorovSmirnov (K-S) test and Shapiro-Wilk test. Both tests show that the measurements are normally distributed. It has been reported that the K-S test has low power, and it should not be seriously considered for testing normality and is very sensitive to extreme values. ${ }^{19}$ For samples smaller than 200, the Shapiro-Wilk test should be used, but for more than 200 either test is used. As we had 46 participants after removal of outliers, although both tests are included, only the Shapiro-Wilk tests were used for the interpretation of the normality of data.

Descriptive statistics for AA measured using the minus-lens-toblur method with the target at different distances are presented in Table 2. The mean AA measured with the target at $6 \mathrm{~m}$ was significantly less than that measured with the near target at $40 \mathrm{~cm}$ or $33 \mathrm{~cm}(p<0.001)$. Sample skewness and kurtosis ${ }^{20}$ are also given in Table 2, and outliers can be seen in Figure 1.

In Table 3, the mean difference measures the absolute difference between the means for two distances ${ }^{20}$ and gives

TABLE 1: Normality tests for the measurements of the amplitude of accommodation indicated that all three samples were normally distributed $(p>0.05)$

\begin{tabular}{lcccccccc}
\hline Distance & \multicolumn{3}{c}{ Kolmogorov-Smirnov } & & \multicolumn{3}{c}{ Shapiro-Wilk } \\
\cline { 2 - 4 } \cline { 7 - 8 } & Statistic & $d f$ & Sig. & & Statistic & $d f$ & Sig. \\
\hline $6 \mathrm{~m}$ & 0.01 & 45 & 0.20 & & 0.99 & 45 & 0.84 \\
$40 \mathrm{~cm}$ & 0.12 & 45 & 0.11 & & 0.91 & 45 & 0.39 \\
$33 \mathrm{~cm}$ & 0.11 & 45 & 0.20 & & 0.93 & 45 & 0.63 \\
\hline
\end{tabular}

Sig., significance, $d f$, degrees of freedom; $m$, metre; $\mathrm{cm}$, centimetre. an idea of how much difference there is between the means of the measured AA for two distances. The mean differences of the AA with the minus-lens-to-blur method when the target was at $6 \mathrm{~m}$ and $40 \mathrm{~cm}$ and at $6 \mathrm{~m}$ and $33 \mathrm{~cm}$ were $-2.16 \pm 1.93$ [CI: -2.73 to -1.59 ] D and $-2.85 \pm 1.85$ [CI: -3.49 to -2.30$] \mathrm{D}$, respectively. The differences were statistically and clinically significant $(p<0.01)$. There was a small mean difference for the AA measured at $40 \mathrm{~cm}$ and $33 \mathrm{~cm}$, which was $-0.69 \pm 0.84$ [CI -0.94 to -0.45$] \mathrm{D}$. The difference of $-0.69 \mathrm{D}$ was statistically significant $(p<0.01)$.

Boxplots (box and whisker diagrams) are a simple and effective way to summarise and display a group or groups

TABLE 2: Descriptive statistics of the means for the amplitude of accommodation using the minus-lens-to-blur method.

\begin{tabular}{|c|c|c|c|c|}
\hline Statistics & $6 \mathrm{~m}$ & $40 \mathrm{~cm}$ & $\begin{array}{c}33 \mathrm{~cm} \text { adding } \\
3.00\end{array}$ & $\begin{array}{c}33 \mathrm{~cm} \text { adding } \\
2.50\end{array}$ \\
\hline Mean \pm s.d. & $8.46 \pm 2.07$ & $10.62 \pm 2.05$ & $11.31 \pm 2.07$ & $11.09 \pm 0.36$ \\
\hline Median & 8.13 & 10.25 & 11.00 & 10.50 \\
\hline \multirow{2}{*}{$\begin{array}{l}95 \% \text { confidence } \\
\text { interval }\end{array}$} & 7.85 & 10.01 & 10.70 & 10.36 \\
\hline & 9.08 & 11.23 & 11.93 & 11.82 \\
\hline Minimum & 7.80 & 10.01 & 10.70 & 6.75 \\
\hline Maximum & 9.00 & 11.22 & 11.93 & 11.50 \\
\hline Skewness & 0.11 & 1.33 & 1.14 & 1.63 \\
\hline Kurtosis & -0.40 & 3.84 & 3.79 & 4.10 \\
\hline Interquartile range & 3.31 & 2.31 & 2.50 & 2.63 \\
\hline $25 \%$ IQR & 6.75 & 9.25 & 10.00 & 9.50 \\
\hline $50 \%$ IQR & 8.13 & 10.25 & 11.00 & 10.50 \\
\hline $75 \%$ IQR & 10.00 & 11.00 & 12.50 & 12.13 \\
\hline
\end{tabular}

Note: The units are in dioptres (D).

s.d., standard deviation; IQR, interquartile (range is the length of the box in each boxplot), $\mathrm{m}$, metre; $\mathrm{cm}$, centimetre.

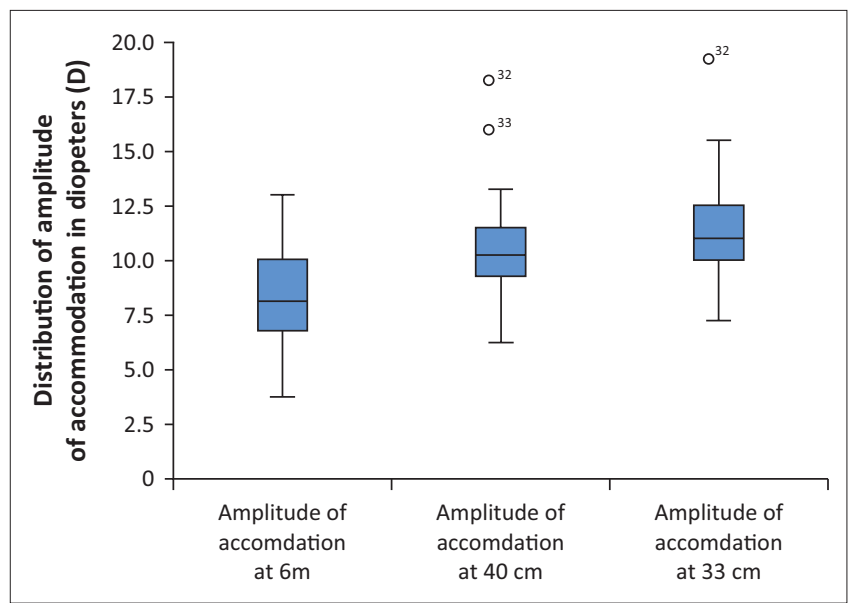

$\mathrm{m}$, metre; cm, centimetre.

FIGURE 1: Boxplots for the measurements of the amplitude of accommodation using the minus lens method with targets at $6 \mathrm{~m}, 40 \mathrm{~cm}$ and $33 \mathrm{~cm}$. The three numbers outside the box are outliers, which are 1.5 times greater than the interquartile range.

TABLE 3: Correlation and mean difference of the amplitude of accommodation in dioptres (D).

\begin{tabular}{lccccc}
\hline Paired distances & $\begin{array}{c}\text { Correlation } \\
(r)\end{array}$ & $p$ & $\begin{array}{c}\text { Mean } \\
\text { difference }\end{array}$ & \multicolumn{2}{c}{$\begin{array}{c}\text { 95\% confidence interval } \\
\text { of the mean difference }\end{array}$} \\
\cline { 5 - 6 } & & & & Low & High \\
\hline $6 \mathrm{~m}$ and $40 \mathrm{~cm}$ & 0.56 & 0.00 & $-2.16 \pm 1.93$ & -2.73 & -1.59 \\
$6 \mathrm{~m}$ and $33 \mathrm{~cm}$ & 0.60 & 0.00 & $-2.85 \pm 1.85$ & -3.40 & -2.30 \\
$40 \mathrm{~cm}$ and $33 \mathrm{~cm}$ & 0.90 & 0.00 & $-0.69 \pm 0.84$ & -0.94 & -0.45 \\
\hline
\end{tabular}

$\mathrm{m}$, metre; $\mathrm{cm}$, centimetre. 
of numerical measurements (see Figure 1), including medians, maxima, minima, and first quartile and third quartiles. ${ }^{21}$ (There were still three outliers left after the removal of the more extreme ones.)

Correlation and linear regression are commonly used for quantifying the association between two numerical variables. ${ }^{22,23}$ Table 3 shows the correlation $(r)$ and mean differences of the AA measured with the target at $6 \mathrm{~m}, 40 \mathrm{~cm}$ and $33 \mathrm{~cm}$. Figures 2-4 are graphical representations of the relationship on the scatter plot. Individual dots represent paired Cartesian coordinates ( $x$ and $y$ values). There is a strong relationship between the AA with the targets at $40 \mathrm{~cm}$ and $33 \mathrm{~cm}$. The bold straight line is the regression line. The dotted lines are the $95 \%$ confidence intervals of the measurements. The significant correlation was observed between the AA measured with the target at $40 \mathrm{~cm}$ and $33 \mathrm{~cm}(r=0.9, p<0.001)$, although the results of the AA measured at $6 \mathrm{~m}$ and $40 \mathrm{~cm}$, and $6 \mathrm{~m}$ and $33 \mathrm{~cm}$ were also correlated (see Table 3 and Figures 2-4).

A value for the correlation greater than 0.7 indicates a strong correlation; values between 0.5 and 0.7 represent

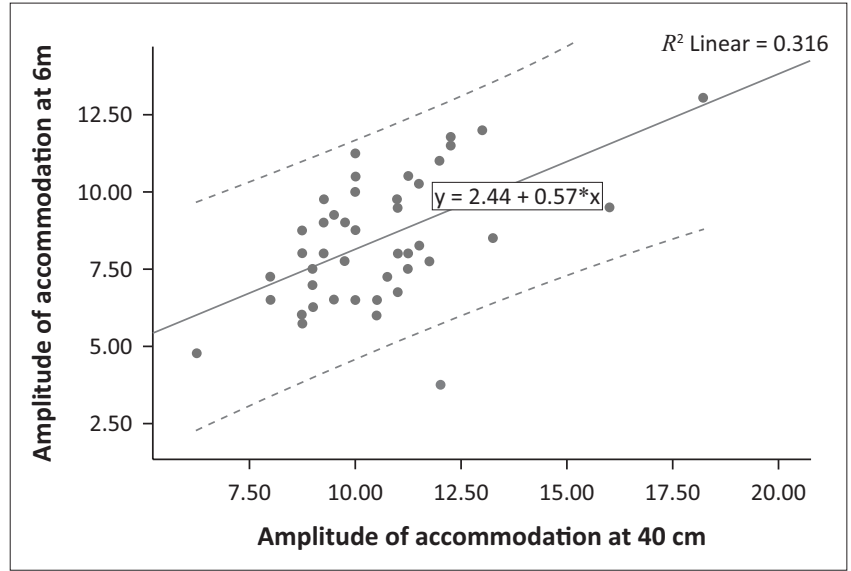

$\mathrm{m}$, metre; $\mathrm{cm}$, centimetre.

FIGURE 2: Linear regression of the amplitude of accommodation measured with the target at $40 \mathrm{~cm}$ against the amplitude of accommodation measured with the target at $6 \mathrm{~m}(r=0.56, p=0.00)$.

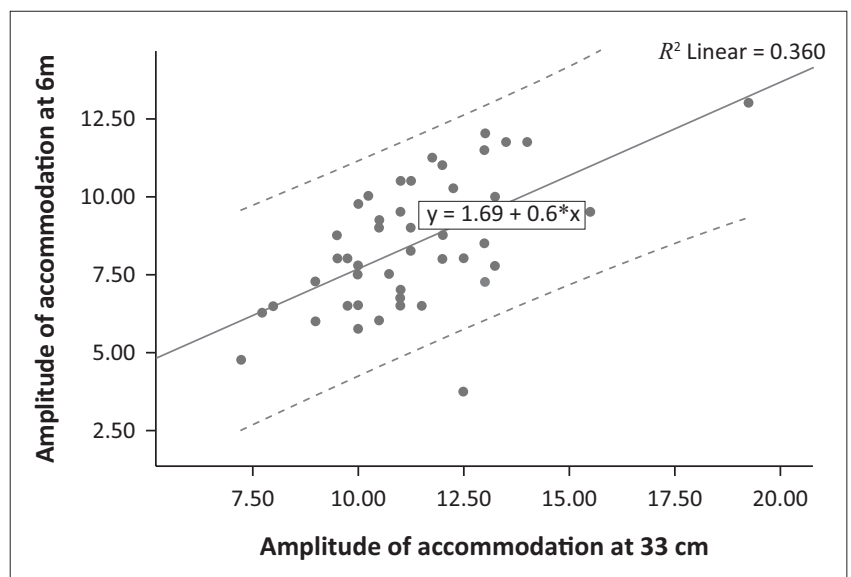

$\mathrm{m}$, metre; $\mathrm{cm}$, centimetre.

FIGURE 3: Linear regression of the amplitude of accommodation measured with the target at $33 \mathrm{~cm}$ against the amplitude of accommodation measured with the target at $6 \mathrm{~m}(r=0.60, p=0.00)$. good correlation. Values between 0.3 and 0.5 may be treated as fair or moderate correlation while any value less than 0.3 would be poor correlation..$^{22,23}$ The linear regression equation $(y=a+b x)$ was calculated and used to predict the values of AA measured at $40 \mathrm{~cm}$ and $33 \mathrm{~cm}$ from the AA measured with the target at $6 \mathrm{~m}$. The following equations could be used to calculate the AA at $40 \mathrm{~cm}$ and $33 \mathrm{~cm}$ from the measured AA with the target at $6 \mathrm{~m}$ :

AA at $40 \mathrm{~cm}=2.44+0.57$

(measured AA with target at $6 \mathrm{~m}$ )

[Eqn 1]

$(\mathrm{F}$ change $=20.35$, residual $=131.705$,

$p<0.05, R^{2}=0.316$, Figure 2).

AA at $33 \mathrm{~cm}=1.68+0.60$

(measured AA with target at $6 \mathrm{~m}$ )

[Eqn 2]

(F change $=24.733$, residual $=123.308$,

$p<0.05, R^{2}=0.36$, Figure 3 )

Correlation is used to assess the degree of association between sets of paired measurements and quantifies the linear relationship between variables. However, it cannot be used to assess comparability between methods. The assessment of agreement is therefore essential in the comparison of the two methods. Bland and Altman recognised the limitation of using correlation in the clinical comparison of two measurement methods. ${ }^{24,25,26}$ The essential feature of a Bland-Altman analysis is that for each pair of measurements, the mean difference $\bar{d}$ between the measurements is plotted against the mean of these measurements. It is expected that most differences would lie within $\bar{d}-1.96$ (s.d.) and $\bar{d}+1.96$ (s.d.). The Bland-Altman plots (see Figures 5-7) are scatter diagrams, where mean differences between measurements are plotted on the $y$-axis. Means (averages) of the measures of the two methods are then plotted on the $x$-axis..$^{24,25,26}$ The overall mean difference obtained (for example, here with the target at two different distances) is called the bias and is represented by the bold

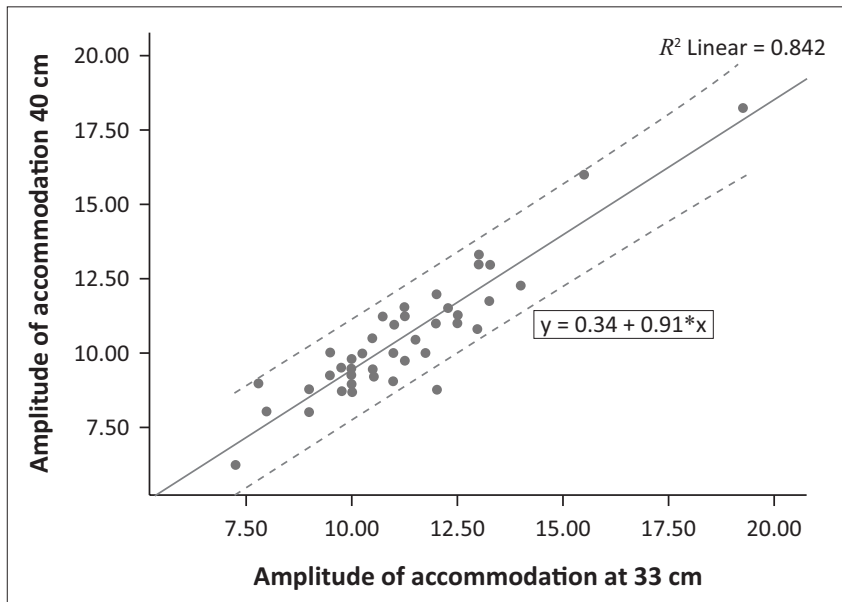

$\mathrm{cm}$, centimetre.

FIGURE 4: Linear regression of the amplitude of accommodation measured with the target at $33 \mathrm{~cm}$ against the amplitude of accommodation measured with the target at $40 \mathrm{~cm}(r=0.90, p=0.00)$. 
central horizontal line on the graph concerned. The standard deviation of the differences between paired measurements were then used to construct the lines denoting 95\% limits of agreement (LoA), ( $\bar{d} \pm 1.96$ [s.d.] of the differences) one horizontal line above and below the bias are called upper and lower LoA. As the LoA are only estimates, confidence intervals were also calculated and plotted on the figure. Firstly, the standard deviation of error of the mean difference \pm 1.95 s.d. was calculated using the following formula:

$\frac{\sqrt{2.92}}{\sqrt{n}}$

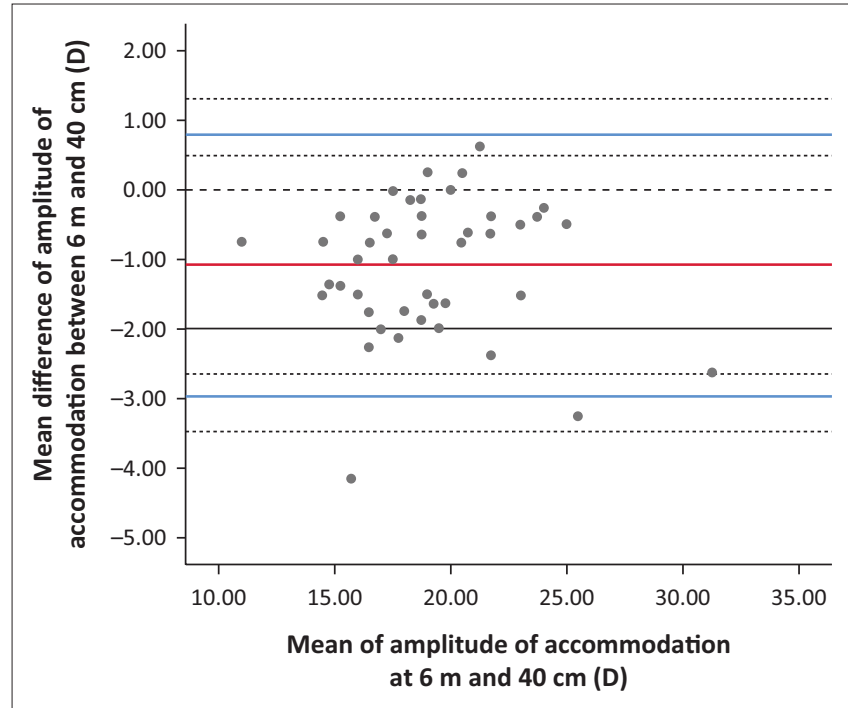

m, metre; cm, centimetre.

FIGURE 5: Bland-Altman plot showing the difference between the amplitude of accommodation at six metres and $40 \mathrm{~cm}$. The bold red line represents the mean difference or bias. The blue solid lines indicate the upper and lower $95 \%$ LoA (bias \pm 1.96 [s.d.]) while the black dotted lines represent the $95 \%$ confidence interval of the upper and lower limits of agreement. LoA, limits of agreement.

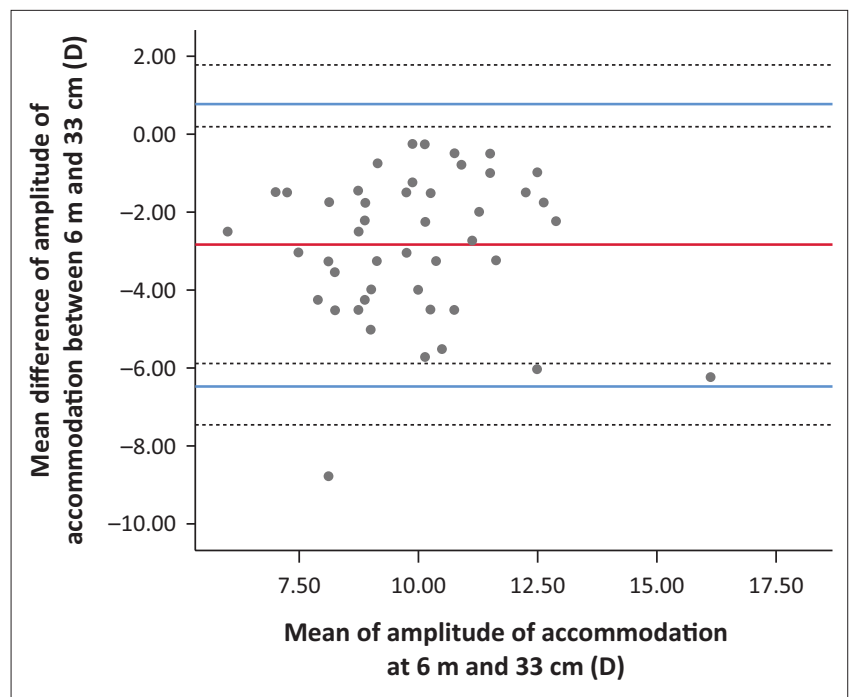

$\mathrm{m}$, metre; $\mathrm{cm}$, centimetre.

FIGURE 6: Bland-Altman plot showing the difference between the amplitude of accommodation at $6 \mathrm{~m}$ and $33 \mathrm{~cm}$. The bold solid line represents the mean difference or bias. for $\gamma=0.975$ and 0.025 , where $n$ is the sample size and using the $t$ distribution table. For 95\% confidence intervals, the degree of freedom $(n-1)=46-1=45$.

The ICC was determined (see Table 4) to assess the reliability or consistent AA measurements with the target at different distances. An ICC is measured on a scale of $0-1$, where 1 represents a stronger or perfect reliability with no measurement error and 0 indicates no reliability. ${ }^{27,28}$ Values above 0.75 indicate strong ICC, values between 0.6 and 0.75 indicate good reliability, values between 0.4 and 0.6 indicate fair or moderate agreement and values less than 0.4 show poor agreement. The ICC differs from the Pearson correlation coefficient in that ICC also takes into account difference in the means of the measures being considered. ${ }^{27}$

The estimated reliability between AA measures with the target at different distances was 0.69 with 95\% CI [0.56-0.80], which is quite wide. The $95 \% \mathrm{CI}$ of the ICC estimate was used to evaluate the level of reliability. Based on the results, the level of reliability was regarded as moderate reliability as $95 \%$ CI of an ICC estimate was in the range of $0.56-0.80$. The Cronbach's alpha (average measure) for the AA measurements with the target at three different distances was 0.87 , suggesting that the measurements have relatively high internal consistency. Although the obtained ICC value is 0.69 , indicating moderate reliability, its $95 \%$ CI ranges between

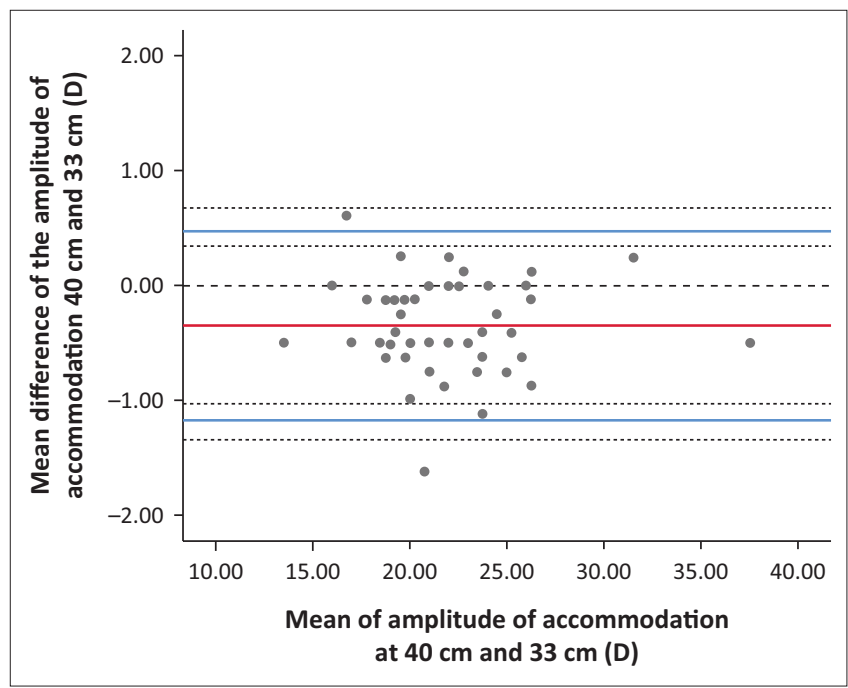

$\mathrm{cm}$, centimetre.

FIGURE 7: Bland-Altman plot showing the difference between the amplitude of accommodation at $40 \mathrm{~cm}$ and $33 \mathrm{~cm}$.

TABLE 4: Intraclass correlation coefficients in the measured amplitude of accommodation using the minus lens method with targets at $6 \mathrm{~m}, 40 \mathrm{~cm}$ or $33 \mathrm{~cm}$, where $n=46$.

\begin{tabular}{|c|c|c|c|c|c|c|c|}
\hline \multirow[t]{2}{*}{ Measure } & \multirow[t]{2}{*}{$\begin{array}{l}\text { Intraclass } \\
\text { correlation }\end{array}$} & \multicolumn{2}{|c|}{$\begin{array}{l}\text { 95\% confidence } \\
\text { interval }\end{array}$} & \multicolumn{4}{|c|}{$F$ test with true value } \\
\hline & & $\begin{array}{l}\text { Lower } \\
\text { bound }\end{array}$ & $\begin{array}{l}\text { Upper } \\
\text { bound }\end{array}$ & Value & df1 & df2 & Sig. \\
\hline Single measure & 0.69 & 0.56 & 0.80 & 7.78 & 45 & 90 & 0.00 \\
\hline Average measure & 0.87 & 0.79 & 0.93 & 7.78 & 45 & 90 & 0.00 \\
\hline
\end{tabular}

Note: Single measure refers to single measurements with the target at $6 \mathrm{~m}, 40 \mathrm{~cm}$ or $33 \mathrm{~cm}$ while the average measure (or Cronbach's alpha) is the average covariance between two measurements and the variance of the total measurements.

Sig., significance; $m$, metre; $\mathrm{cm}$, centimetre. 
0.56 and 0.80 , meaning that there is $95 \%$ chance that the true ICC value could land on any point between 0.56 and 0.80 . Therefore, it was appropriate to conclude that the level of reliability was moderate to good.

\section{Discussion}

The accommodative system of the human eye is highly complicated but necessary to execute and carry out very fine and detailed near work. The healthy eye alone does not always guarantee provision of clear and comfortable vision for an individual within a given distance of fixation.

This study showed that the measured AA with the target at $6 \mathrm{~m}$ was significantly lower than with the target at $40 \mathrm{~cm}$ and $33 \mathrm{~cm}$. The mean difference was $-2.16 \pm 1.93 \mathrm{D},-2.85 \pm 1.85$ $\mathrm{D}$ and $-0.70 \pm 0.84 \mathrm{D}$ when the target distance was at $6 \mathrm{~m}$ and $40 \mathrm{~cm}, 6 \mathrm{~m}$ and $33 \mathrm{~cm}$ and lastly $40 \mathrm{~cm}$ and $33 \mathrm{~cm}$. All the comparisons were statistically correlated and clinically significant $(p<0.05)$. The cause of this significant mean difference when the target was at far and near is unknown but could be due to the proximal cues and accommodative effort when the target was held at near $(40 \mathrm{~cm}$ and $33 \mathrm{~cm}$ ). Perhaps the lower AA could be attributed to tonic accommodation or lack of convergence accommodation when the target was at $6 \mathrm{~m} \cdot{ }^{16,29,30}$ Even though there was a correlation between the measured AA with target at $6 \mathrm{~m}$ and $40 \mathrm{~cm},(r=0.50), 6 \mathrm{~m}$ and $33 \mathrm{~cm}(r=0.60)$, there was a weaker agreement between those measurements (see Figures 5-7). This shows that the measured AA with the minus-lens-toblur method with the target at far and near are not interchangeable.

The difference between the AA measured with target at $40 \mathrm{~cm}$ and $33 \mathrm{~cm}$ can vary by about $0.70 \mathrm{D}$. When working at more proximal distances, the target subtends a larger angle at the eye due to a smaller pupil size and larger depth of focus. Such an increase in depth of focus could delay the appreciation of blur, hence resulting in a higher measurement of AA at $33 \mathrm{~cm}$. This is not due to an increased accommodation but rather delay in the perception of blur.

However, the formula was determined to exploit the possibility of using the measured AA with the minus-lens-toblur method with the target at $6 \mathrm{~m}$ to calculate for the AA at $40 \mathrm{~cm}$ and $33 \mathrm{~cm}$. The other purpose of the study was to investigate the possibility of using a formula to calculate the AA at $40 \mathrm{~cm}$ and $33 \mathrm{~cm}$ based on the measured AA with the target at $6 \mathrm{~m}$. The results of the calculated AA at $40 \mathrm{~cm}$ and $33 \mathrm{~cm}$ from the results of the measured AA with the target at $6 \mathrm{~cm}$ will be correct or useful only in $31.6 \%$ and $36.0 \%$ of the study subjects, respectively (see Figures 2 and 3 ).

The purpose of measuring the AA is to obtain the maximum accommodation at a near-viewing distance. Hence, AA was also measured at $33 \mathrm{~cm}$ which is the average reading distance of most scholars and pre-presbyopic individuals. ${ }^{15,16}$ The results of this study showed that the mean AA measured at $33 \mathrm{~cm}$ was significantly higher when compared with the measurement with the target at $40 \mathrm{~cm}$. The mean difference was $-0.70 \pm 0.84, p=0.00$ (see Tables 2 and 3). As most prepresbyopic individuals read at $33 \mathrm{~cm}$, the use of $40 \mathrm{~cm}$ as a near-testing distance for all pre-presbyopic patients may be inappropriate and give incorrect results. ${ }^{15}$ Although $40 \mathrm{~cm}$ is used as a standard near-testing distance, the use of cellphones and tablets has changed the viewing conditions, and closer testing distances might be more appropriate.

The results of this study agree with the findings of MomeniMaghaddam et al. ${ }^{11,12}$ who found that the AA measured at $33 \mathrm{~cm}$ was higher than that with the target at $40 \mathrm{~cm}$, and the mean difference was $1.17 \mathrm{D}$ on average. In this study, the mean difference between the AA measured using minuslens-to-blur method with the target at $40 \mathrm{~cm}$ and $33 \mathrm{~cm}$ was $-0.70 \pm 0.84 \mathrm{D}$. The minus lens technique is one of the subjective techniques for measuring the AA and like other subjective methods tends to overestimate the true AA, mainly due to depth of focus, target and pupil size and illumination. ${ }^{7,13}$ So the possible cause of higher mean AA at $33 \mathrm{~cm}$ when compared with $40 \mathrm{~cm}$ could be convergence accommodation and/or proximally induced accommodation with pupil constrictions. ${ }^{16}$

The increased use of small display-screen devices (smartphones) is associated with high levels of accommodation and can lead to more load on the accommodative system than with conventional near-vision tasks. ${ }^{29}$ The analysis of visual efficiency for contemporary vision tasks would require precise measurement of AA as the tasks may require maximal levels of accommodation.

When $2.50 \mathrm{D}$ was added in this study, the mean result of AA with target at $33 \mathrm{~cm}$ decreased by an average of $1.20 \mathrm{D}$ from 11.31 D to $11.09 \mathrm{D}$ (see Table 2). A study by Taub and ShalloHoffmann $^{14}$ used the target distance of $33 \mathrm{~cm}$ and added 2.50 to the result to determine the final AA. However, they questioned whether the result of their study would have been different had they used 3.00 D instead of 2.50 D. Based on the results of this study, even the results of Taub and Shallo-Hoffmann ${ }^{14}$ would have been different (increased) had they added 3.00 D instead.

The objective measure of reliability is the Cronbach's alpha, ${ }^{31}$ which provides a measure of the internal consistency of a test (how closely related are the measurements of AA as a group). ${ }^{31}$ Internal consistency describes the extent to which all the items in a test measure the same concept. The acceptable value of alpha ranges from 0.7 to 0.95 ; however, some researchers recommend that the maximum value should be 0.90 . If the alpha is too high above 0.90 , it may suggest that some measurements are redundant. ${ }^{31}$

\section{Conclusion}

The results of this study demonstrate that the AA measured with the target closer to eyes produced a larger increase in accommodation. As a consequence of increasing near-vision demands, in modern society, the use of $40 \mathrm{~cm}$ as a near-test 
distance for pre-presbyopic subjects may no longer be appropriate. Measurements should perhaps be done at $33 \mathrm{~cm}$; however, more studies are required to evaluate the appropriate distance for performing near tests, including the AA using the minus-lens-to-blur method. The agreement of the AA was weaker when measured with targets at far and near, indicating that the methods are not necessarily interchangeable.

\section{Acknowledgements}

This article is based on the fourth-year optometric research project. The authors wish to extend their gratitude to all who volunteered to participate in the study.

\section{Competing interests}

The authors declare that they have no financial or personal relationships that may have inappropriately influenced them in writing this article.

\section{Authors' contributions}

M.Z.G.N. performed the measurements and drafted the original manuscript. K.T.M. performed the measurements and proofread the original manuscript. M.H.K. recorded the measurements and entered them in the SPSS. M.S.T. drafted the original manuscript and performed the literature review and S.D.M. performed the statistical analysis and proofread the final draft. All authors then proofread the final manuscript.

\section{Funding information}

The work reported in this article was funded by the South African Medical Research Council to S.D.M.

\section{Disclaimer}

The views and opinions expressed in this article are those of the authors and do not necessarily reflect the official policy or position of any affiliated agency of the authors.

\section{References}

1. Anderson HA, Stuebing KK. Subjective vs objective accommodative amplitude: Preschool to presbyopia. Optom Vis Sci. 2014;91(11):1290-1301.

2. Lopez-Gil N, Fernandez-Sanchez V, Thibos LN, Montes-Micoh R. Objective amplitude of accommodation computed from optical quality matrix applied to wavefront outcomes. J Optom. 2009;2(4):223-234. https://doi.org/10.3921/ joptom.2009.223

3. Goss DA. Clinical accommodation testing. Curr Opin Ophthalmol. 1992;3(1) 78-82.

4. Ostrin LA, Glasser A. Accommodation measurements in prepresbyopic and presbyopic population. J Cataract Refract Surg. 2004;30(7):1435-1444. https://doi. org/10.1016/j.jcrs.2003.12.045
5. Wold JE, Hu A, Chen S, Glasser A. Subjective and objective measurement of human accommodative amplitude. J Cataract Refract Surg. 2003;29(10): 1878-1888.

6. Rabbetts RB. Bennett \& Rabbetts' clinical visual optics. 4th ed. London: Butterworth-Heinemann; 2007.

7. Atchison DA, Capper EJ, McCabe KL. Critical subjective measurement of amplitude of accommodation. Optom Vis Sci.1994;71(11):699-706.

8. Momeni-Maghaddam H, Kundart J, Askarizodeh F. Comparing measurement techniques of accommodative amplitude. Indian J Ophthalmol. 2014;62(6): 683-687. https://doi.org/10.4103/0301-4738.126990

9. Anderson HA, Hentz G Glasser A, Stuebing KK, Manny RE. Minus-lens-stimulated accommodative amplitude decreases sigmoidally with age: A study of objectively measured accommodative amplitude from age 3. Invest Ophthalmol Vis Sci. 2008;49(7):2919-2926. https://doi.org/10.1167/iovs.07-1492

10. Rosenfield $\mathrm{M}$, Cohen AS. Push-up amplitude of accommodation and target size. Ophthalmic Physiol Opt. 2017;15(3):231-232.

11. Momeni-Maghaddam $H$, Ng JS, Cesana BM, Yekta AA, Sedaghat MR. Accommodative amplitude using the minus lens at different near distances. Indian J Ophthalmol. 2014;65(3):223-227. https://doi.org/10.4103/ijo.IJO 545_16

12. Momeni-Maghaddam $\mathrm{H}$, Wolffsohn JS, Azimi A, Babdie-Mohekkolaei E. Effect of target distance on accommodative amplitude measured using minus lens technique. Clin Exp Optom. 2014;97(1):62-65. https://doi.org/10.1111/ cxo.12090

13. Mathebula SD, Ntsoane MD, Makgaba NT, Landela KL. Comparison of the amplitude of accommodation determined subjectively and objectively in South African university students. Afr Vis Eye Health. 2018;77(1):a437. https://doi. org/10.4102/aveh.v77i1.437

14. Taub MB, Shallo-Hoffmann JA. A comparison of three clinical tests of accommodation amplitude to Hofstetter's norms to guide diagnosis and treatment. Optom Vis Dev. 2012;43(4):180-190.

15. Bababekova $Y$, Rosenfield M, Hue JE, Husng RR. Font size and viewing distances of handheld smart phones. Optom Vis Sc. 2011;88(7):795-797. https://doi. org/10.1097/OPX.0b013e3182198792.

16. Rosenfield M, Wong NN, Solan HA. Nearwork distances in children. Ophthalmic Physiol Opt. 2001;21(1):75-76. https://doi.org/10.1046/j.1475-1313.2001.00566.x

17. Woods CA, Dumbleton K, Jones L. Patients use of smartphones to communicate subjective data in clinical trials. Optom Vis Sci. 2011,88(2):290-294. https://doi. org/10.1097/OPX.0b013e3181ff9b80

18. Scheiman M, Wick B. Clinical management of binocular vision: Heterophoria, accommodation, and eye movement disorders. 3rd ed. Philadelphia, PA: Lippincott Williams \& Wilkins; 2008.

19. Ghasemi A, Zahediasl S. Normality tests for statistical analysis: A guide for nonstatisticians. Int J Endocrinol Met. 2012;10(2):486-489. https://doi.org/10.5812/ ijem.3505

20. Joanes DN, Gill CA. Comparing measures of skewness and kurtosis. J Royal Statistical Soc: Series D. 1998;47(1):183-189.

21. Liu Y. Box plots: Use and interpretation. Transfusion. 2008;48(11):2278-2280.

22. Bewick V, Cheek L, Ball L. Statistical review 7: Correlation and regression. Crit Care. 2003;7(6):451-459. https://doi.org/10.1186/cc2401

23. Bunce C. Correlation, agreement and Bland-Altman analysis: Statistical analysis of methods comparison studies. Am J Ophthalmal. 2009;148(1):4-6. https://doi. org/10.1016/j.ajo.2008.09.032

24. Bland JM, Altman DG. Statistical methods for assessing agreement between two methods of clinical measurement. Lancet. 1986;1(8476):307-310.

25. Giavarina D. Understanding Bland Altman analysis. Biochem Med. 2015;25(2): 141-151. https://doi.org/10.11613/BM.2015.015

26. Carkeet A. Exact parametric confidence interval for Bland-Altman limits of agreement. Optom Vis Sci. 2015;92(3):e71-e80. https://doi.org/10.1097/OPX 0000000000000513

27. Landers R. Computing intraclass correlation (ICC) as estimates of interrater reliability in SPSS. The Winnower. 2015;2:e143518.81744.

28. Koo TK, Li MY. A guideline of selecting and reporting intraclass correlation coefficients for reliability research. JCM. 2016;15:155-163. https://doi.org/ 10.1016/j.jcm.2016.02.012

29. Liu C, Drew SA, Borsting E. Tonic accommodation predicts closed-loop accommodation response. J Vis Res. 2016;129:25-32. https://doi.org/10.1016/ j.visres.2016.08.010

30. Rosenfield M, Gilmartin B. Effect of target proximity on the open-loop accommodative response. Optom Vis Sci. 1990;67:74-79.

31. Tavakol M, Dennick R. Making sense of Cronbach's alpha. Int J Med Educ. 2011;2:53-55. https://doi.org/10.5116/ijme.4dfb.8dfd 